\title{
Precision Farming: The Future of Indian Agriculture
}

\author{
V. M. Abdul Hakkim ${ }^{1,2}$, E. Abhilash Joseph ${ }^{1 *}$, A. J. Ajay Gokul ${ }^{2}$, K. Mufeedha ${ }^{1}$ \\ ${ }^{1}$ Precision Farming Development Centre (PFDC), Kelappaji College of Agricultural Engineering and Technology (KCAET), Kerala Agricultural \\ University, Tavanur P.O, Malappuram, Kerala, India. ${ }^{2}$ Department of Land \& Water and Conservation Engineering (LWRCE), Kelappaji College of \\ Agricultural Engineering and Technology (KCAET), Kerala Agricultural University, Tavanur P.O, Malappuram, Kerala, India.
}

\section{ARTICLE INFO}

\section{Article history:}

Received on: 08/07/2016

Revised on: 04/08/2016

Accepted on: 20/08/2016

Available online: 05/11/2016

Key words:

Crop management, hi-tech

agriculture, variable rate

technology, precision

farming.

\begin{abstract}
Precision Farming or Precision Agriculture is generally defined as information and technology based farm management system to identify, analyse and manage spatial and temporal variability within fields for optimum productivity and profitability, sustainability and protection of the land resource by minimizing the production costs. Increasing environmental consciousness of the general public is necessitating us to modify agricultural management practices for sustainable conservation of natural resources such as water, air and soil quality, while staying economically profitable. The use of inputs (i.e. chemical fertilizers and pesticides) based on the right quantity, at the right time, and in the right place. This type of management is commonly known as "Site-Specific Management". The productivity gain in global food supply have increasingly relied on expansion of irrigation schemes over recent decades, with more than a third of the world's food now requiring irrigation for production. All-together, market-based global competition in agricultural products is challenging economic viability of the traditional agricultural systems, and requires the development of new and dynamic production systems.
\end{abstract}

\section{INTRODUCTION}

Precision farming is an approach where inputs are utilised in precise amounts to get increased average yields compared to traditional cultivation techniques. Hence it is a comprehensive system designed to optimize production by using a key elements of information, technology, and management, so as to increase production efficiency, improve product quality, improve the efficiency of crop chemical use, conserve energy and protect environment [1]. Thus, precision farming is an appealing concept and its principles quite naturally lead to the expectation that farming inputs can be used more effectively, with subsequent improvements in profits and environmentally less burdensome production. The precision farming developments of today can provide the technology for the environment friendly agriculture of tomorrow. Especially in the case of small farmers in

* Corresponding Author

Abhilash Joseph E., Precision Farming Development Centre (PFDC), Kelappaji College of Agricultural Engineering and Technology

(KCAET), Kerala Agricultural University, Tavanur P.O, Malappuram,

Kerala, India.Email:abhilashjosephe@gmail.com developing countries, precision farming holds the promise of substantial yield improvement with minimal external input use [2].

\section{NEED OF PRECISION FARMING}

The global food system faces formidable challenges today that will increase markedly over the next 40 years. Much can be achieved immediately with current technologies and knowledge, given sufficient will and investment. But coping with future challenges will require more radical changes to the food system and investment in research to provide new solutions to novel problems. The decline in the total productivity, diminishing and degrading natural resources, stagnating farm incomes, lack of ecoregional approach, declining and fragmented land holdings, trade liberalization on agriculture, limited employment opportunities in non-farm sector, and global climatic variation have become major concerns in agricultural growth and development. Therefore, the use of newly emerged technology adoption is seen as one key to increase agriculture productivity in the future. Instead of managing an entire field based upon some hypothetical average condition, which may not exist anywhere in the field, a precision farming approach recognizes site-specific differences within fields and adjusts management actions accordingly. Farmers usually are aware that their fields have variable yields across the landscape. 
These variations can be traced to management practices, soil properties and/or environmental characteristics. The level of knowledge of field conditions is difficult to maintain because of the large sizes and changes due to annual shifts in leasing arrangements in the farm area. So the entire farm area has to be divided into small farm units of 50 cents or less. Precision agriculture offers the potential to automate and simplify the collection and analysis of information. It allows management decisions to be made and quickly implemented on small areas within larger fields.

\section{TOOLS AND EQUIPMENT}

\subsection{Global positioning system (GPS)}

GPS is a navigation system based on a network of satellites that helps users to record positional information (latitude, longitude and elevation) with an accuracy of between 100 and 0.01 $\mathrm{m}$ [3]. GPS allows farmers to locate the exact position of field information, such as soil type, pest occurrence, weed invasion, water holes, boundaries and obstructions. There is an automatic controlling system, with light or sound guiding panel (DGPS), antenna and receiver. GPS satellites broadcast signals that allow GPS receivers to calculate their position. The system allows farmers to reliably identify field locations so that inputs (seeds, fertilizers, pesticides, herbicides and irrigation water) can be applied to an individual field, based on performance criteria and previous input applications [4].

\subsection{Sensor technologies}

Various technologies such as electromagnetic, conductivity, photo electricity and ultra sound are used to measure humidity, vegetation, temperature, texture, structure, physical character, humidity, nutrient level, vapour, air etc. Remote sensing data are used to distinguish crop species, locate stress conditions, identify pests and weeds, and monitor drought, soil and plant conditions. Sensors enable the collection of immense quantities of data without laboratory analysis [5].

\subsection{Geographic information system (GIS)}

This system comprises hardware, software and procedures designed to support the compilation, storage, retrieval and analysis of feature attributes and location data to produce maps. GIS links information in one place so that it can be extrapolated when needed. Computerized GIS maps are different from conventional maps and contain various layers of information (e.g. yield, soil survey maps, rainfall, crops, soil nutrient levels and pests). GIS is a kind of computerized map, but its real role is using statistics and spatial methods to analyse characters and geography. A farming GIS database can provide information on filed topography, soil types, surface drainage, subsurface drainage, soil testing, irrigation, chemical application rates and crop yield. Once analysed, this information is used to understand the relationships between the various elements affecting a crop on a specific site [6]. In addition to data storage and display, the GIS can be used to evaluate present and alternative management by combining and manipulating data layers to produce an analysis of management scenarios.

\subsection{Grid soil sampling and variable-rate fertilizer (VRT) application}

Variable-rate technologies (VRT) are automatic and may be applied to numerous farming operations. VRT systems set the rate of delivery of farm inputs depending on the soil type noted in a soil map. Information extrapolated from the GIS can control processes, such as seeding, fertilizer and pesticide application, herbicide selection and application at a variable rate in the right place at the right time. VRT is perhaps the most widely used PFS technology in the United States [4]. Grid soil sampling uses the same principles of soil sampling but increases the intensity of sampling. Soil samples collected in a systematic grid also have location information that allows the data to be mapped. The goal of grid soil sampling is a map of nutrient needs, called an application map. Samples may be collected for more than one area of a field which fall in to the same range of yield, soil colour, etc. and thus the same zone. Grid soil samples are analysed in the laboratory, and an interpretation of crop nutrient needs is made for each soil sample. Then the fertilizer application map is plotted using the entire set of soil samples. The application map is loaded into a computer mounted on a variable-rate fertilizer spreader. The computer uses the application map and a GPS receiver to direct a product-delivery controller that changes the amount and/or kind of fertilizer product, according to the application map $[7,8]$.

\subsection{Crop management}

Satellite data provide farmers a better understanding of the variation in soil conditions and topography that influence crop performance within the field. Farmers can, therefore, precisely manage production factors, such as seeds, fertilizers, pesticides, herbicides and water control, to increase yield and efficiency.

\subsection{Soil and plant sensors}

Sensor technology is an important component of precision agriculture technology and their use has been widely reported to provide information on soil properties and plant fertility/water status. A comprehensive list of current sensors as well as desirable features for new sensors to be developed in the future [9].

One of the most popular ways to characterize soil variability is surveying the field with soil apparent electrical conductivity (ECa) sensors that collect information continuously when pulled over the field surface. Because ECa is sensitive to changes in soil texture and salinity, these sensors provide an excellent baseline to implement site-specific management.

\subsection{Global Positioning System (GPS)}

Global Positioning System satellites broadcast signals that allow GPS receivers to calculate their position. This information is provided in real time, meaning that continuous 
position information is provided while in motion. Having precise location information at any time allows soil and crop measurements to be mapped. GPS receivers, either carried to the field or mounted on implements allow users to return to specific locations to sample or treat those areas. Uncorrected GPS signals have an accuracy of about 300 feet.

\subsection{Rate controllers}

Rate controllers are devices designed to control the delivery rate of chemical inputs such as fertilizers and pesticides, either liquid or granular. These rate controllers monitor the speed of the tractor/sprayer traveling across the field, as well as the flow rate and pressure (if liquid) of the material, making delivery adjustments in real-time to apply a target rate. Rate controllers have been available for some time and are frequently used as stand-alone systems.

\subsection{Precision irrigation in pressurized systems}

Recent developments are being released for commercial use in sprinkler irrigation by controlling the irrigation machines motion with GPS based controllers. In addition to motion control, wireless communication and sensor technologies are being developed to monitor soil and ambient conditions, along with operation parameters of the irrigation machines (i.e. flow and pressure) to achieve higher water application efficiency and utilization by the crop. These technologies show remarkable potential but further development is needed before they become commercially available.

\subsection{Software}

Applying precision agriculture technologies will frequently require the use of software to carry out diverse tasks such as display-controller interfacing, information layers mapping, pre and post processing data analysis and interpretation, farm accounting of inputs per field, and many others. The most common are software to generate maps (e.g. yield, soil); software to filtering collected data; software to generate variable rate applications maps (e.g. for fertilizer, lime, chemicals); software to overlay different maps; and software to provide advanced geostatistical features.

All are excellent options for precision agriculture farm management and record keeping to keep up with the needs of modern, information-intensive farming systems. There are a few companies that operate world-wide and provide integrated software packages from generating all different types of maps, having statistical analysis tools and also record keeping. The machinery companies that provide yield meters also offer software to generate yield maps and fertilizer companies provide software to generate variable rate applications maps. Some of the packages are very complicated for farmers to use and they are fairly expensive, while some others are considerably simpler and cheaper with fewer options. The packages are more user-friendly and have many options for the farmer to use. However, there are still problems related to data transfer between farmers, and between farmer, co-op and consultant. To overlay maps, mainly soil and yield maps, is also a difficult task so far.

\subsection{Yield monitor}

Yield monitors are a combination of several components. They typically include several different sensors and other components, including a data storage device, user interface (display and key pad), and a task computer located in the combine cab, which controls the integration and interaction of these components. The sensors measure the mass or the volume of grain flow (grain flow sensors), separator speed, ground speed, grain. In the case of grains, yield is continuously recorded by measuring the force of the grain flow as it impacts a sensible plate in the clean grain elevator of the combine.

A recent development of a mass flow sensor works on the principle of transmitting beams of microwave energy and measuring the portion of that energy that bounces back after hitting the stream of seeds flowing through the chutes. In all yield monitors, GPS receivers are used to record the location of yield data and create yield maps. Other yield monitoring systems include devices used in forage crops to keep track of weight, moisture, and other information on a per-bale basis [10].

\subsection{Precision farming on arable land}

The use of PA techniques on arable land is the most widely used and most advanced amongst farmers [11]. CTF is a whole farm approach that aims at avoiding unnecessary crop damage and soil compaction by heavy machinery, reducing costs imposed by standard methods. Controlled traffic methods involve confining all field vehicles to the minimal area of permanent traffic lanes with the aid of GNSS technology and decision support systems.

Another important application of precision agriculture in arable land is to optimise the use of fertilizers, starting with the three main nutrients Nitrogen, Phosphorus and Potassium. In conventional farming these fertilizers are applied uniformly over fields at certain times during the year. This leads to overapplication in some places and under-application in others. The environmental cost is directly related to over-application which allows nitrogen and phosphorus leaching from the field into ground- and surface waters or to other areas of the field where they are not desired.

With the use of precision agriculture methods, fertilizers can be applied in more precise amounts, with a spatial and temporal component to optimize the application. The technology that allows the farmer to control the amount of inputs in arable lands is the Variable Rate Application (VRA), which combines a variable-rate (VR) control system with application equipment to apply inputs at a precise time and/or location to achieve sitespecific application rates of inputs. VRs are decided on the basis of prior measurement, e.g. from remote sensing or machine mounted sensors. 


\subsection{Precision farming within the fruits \& vegetables and viticulture sectors}

In fruit and vegetable farming the recent rapid adoption of machine vision methods allows growers to grade products and to monitor food quality and safety, with automation systems recording parameters related to product quality. These include colour, size, shape, external defects, sugar content, acidity, and other internal qualities [12]. Additionally, tracking of field operations such as chemicals sprayed and use of fertilizers can be possible to provide complete fruit and vegetable processing methods.

This information can be disclosed to consumers for risk management and for food traceability as well as to producers for precision agriculture to get higher quality and larger yields with optimized inputs. In recent years several new approaches were developed that take into account the actual size of the tree, the condition of the crop, but also the environmental conditions [13].

The development and adoption of PA technologies and methodologies in viticulture (termed Precision Viticulture, PV) is more recent than in arable land. However, driven by the high value of the crop and the importance of quality, several research projects already exist in wine production areas of the world [14,15]. Grape quality and yield maps are of great importance during harvest to avoid mixing grapes of different potential wine qualities. The parcels with greatest opportunities for PV are those which reveal a high degree of yield variation. A high degree of variation will mean higher VRA of inputs and, therefore, greater economic and environmental benefit in comparison with uniform management.

\subsection{Precision livestock farming (PLF)}

Precision livestock farming (PLF) is defined as the management of livestock production using the principles and technology from precision agriculture. Processes suitable for the precision livestock farming approach include animal growth, milk and egg production, detection and monitoring of diseases and aspects related to animal behaviour and the physical environment such as the thermal micro-environment and emissions of gaseous pollutants. Systems include milk monitoring to check fat and microbial levels, helping to indicate potential infections, as well as new robotic feeding systems, weighing systems, robotic cleaners, feed pushers and other aids for the stockman such as imaging systems to avoid direct contact with animals. New systems for data monitoring for feed and water consumption can be used to the early detection of infections is available now. Other developments include the monitoring on the growing herd where measurement of growth in real time is important to provide producers with feed conversion and growth rates. Acoustic sensors detect an increase in coughing of pigs as an indicator of respiratory infection. Other sensors are now used to provide alerts concerning birthing and fertility.

A vaginal thermometer monitors the temperature, imminence of birthing and the breaking of waters, and communicates to the farmer via SMS. Also, a sensor placed on an animal's collar records parameters to detect signs of oestrus and the readiness for fertilisation. An SMS message then allows the farmer to plan for insemination.

\subsection{On-line resources for precision agriculture}

There is a wealth of information available over the internet on new technology for farm production. Most manufacturers of farm equipment, GPS receivers, sensors, and other PA technologies use this media to inform growers on new products, technical specifications, trouble-shooting information, software upgrades, and a variety of services.

\section{CONCLUSION}

Precision farming is still only a concept in many developing countries and strategic support from the public and private sectors is essential to promote its rapid adoption. Successful adoption, however, comprises at least three phases including exploration, analysis and execution. Precision agriculture can address both economic and environmental issues that surround production agriculture today. Questions remain about cost-effectiveness and the most effective ways to use the technological tools we now have, but the concept of "doing the right thing in the right place at the right time" has a strong intuitive appeal. In the light of today's urgent need, there should be an allout effort to use new technological inputs to make the 'Green Revolution' as an 'Evergreen Revolution'. Ultimately, the success of precision agriculture depends largely on how well and how quickly the knowledge needed to guide the new technologies can be found.

Precision farming provides a new solution using a systems approach for today's agricultural issues such as the need to balance productivity with environmental concerns. It is based on advanced information technology. It includes describing and modelling variation in soils and plant species, and integrating agricultural practices to meet site-specific requirements. It aims at increased economic returns, as well as at reducing the energy input and the environmental impact of agriculture.

\section{ACKNOWLEDGEMENT}

The authors are thankful to the Kerala Agricultural University and the Dean, Kelappaji College of Agricultural Engineering and Technology (KCAET), Tavanur for providing necessary facilities and support for the preparation of the manuscript.

\section{Financial support and sponsorship: Nil.}

Conflict of Interests: There are no conflicts of interest.

\section{REFERENCES}

1. Shibusawa S. Precision farming approaches to small farm agriculture Agro-Chemicals Report. 2002; 2(4):13-20.

2. Fountas S, Ess D, Sorensen CG, Hawkins S, Pedersen $\mathrm{HH}$, Blackmore S, Deboer LJ, Farmer experience with Precision 
Agriculture in Denmark and US Eastern Corn Belt. Precision Agriculture. 2004.

3. Lang L. GPS, GIS, remote sensing: An overview. Earth Observation Magazine. 1992; 23-26.

4. Batte MT, Van Buren FN. Precision farming - Factor influencingproductivity. In Northern Ohio Crops Day meeting, Wood County, Ohio, 21 Jan. 1999.

5. Chen F, Kissel DE, Clark R, West LT, Rickman D, Luval J, Adkin W. Determining surface soil clay concentration at a field scale for precision agriculture, University of Georgia, Huntsville. 1997.

6. Trimble. 2005. Precision agriculture. Available at: www.trimble.com.

7. Berntsen J, Thomsen A, Schelde K, Hansen OM, Knudsen L, Broge $\mathrm{N}$, Hougaard H, Horfarter R. Algorithms for sensor-based redistribution of nitrogen fertilizer in winter wheat. Precision Agriculture. 2006; 7: 65-83.

8. Ferguson R., Dobermann, A. and Schepers, J. 2007. Precision agriculture: site-specific nitrogen management for irrigated corn. University of Nebraska Lincoln Extension. Bulletin.1-7.

9. Adamchuk VI, Hummel JW, Morgan MT, Upadhyaya SK. On-the-go soil sensors for precision agriculture. Computers and Electronics in Agriculture. 2004; 44: 71-91.

10. Davis G, Massey R, Massey R. Precision agriculture: An introduction. www.muextension.missouri.edu/explore/envqual/ wq0450.htm. 2005.

11. Bowman K. Economic and environmental analysis of converting to controlled traffic farming, In $6^{\text {th }}$ Australian Controlled Traffic Farming Conference, 2008. 61-68.
12. Njoroge JB, Ninomiya K, Kondo N. Automated fruit grading system using image processing, In Proceedings of the $41^{\text {st }}$ SICE Annual Conference. 2002; 1346-1351.

13. Doruchowski G, Balsari P, Zande JC. Precise spray application in fruit growing according to crop health status, target characteristics and environmental circumstances; Proc. of $8^{\text {th }}$ Fruit, Nut and Vegetable Production Engineering Symposium, Concepcion-Chile. 2009; 494-502.

14. Ojeda H, Carrillo N, Deis L. Precision viticulture and water status II: Quantitative and qualitative performance of different within field zones, defined from water potential mapping, in XIV International GESCO Viticulture Congress, Geisenheim, Germany, 2005. 741-748.

15. Ferreiro-Arman M, Da Costa JP, Homayouni S. Hyperspectral image analysis for precision viticulture, In Image Analysis and Recognition, Springer Berlin Heidelberg. 2006; pp. 730-741.

\section{How to cite this article:}

Abdul Hakkim V.M, Abhilash Joseph E., Ajay Gokul AJ, Mufeedha K. Precision Farming: The Future of Indian Agriculture. J App Biol Biotech. 2016; 4 (06): 068-072. DOI: 10.7324/JABB.2016.40609 